\title{
Requirement for Binding of Catalytically Active Factor VIla in Tissue Factor-dependent Experimental Metastasis
}

\author{
Barbara M. Mueller and Wolfram Ruf \\ Department of Immunology and Department of Vascular Biology, The Scripps Research Institute, La Jolla, California 92037
}

\begin{abstract}
Tissue factor (TF), the initiating cell surface receptor of the coagulation cascade, plays important roles in embryogenesis, angiogenesis, and tumor cell metastasis. It is controversial whether proteolytic function of TF complexed with its serine protease ligand VIIa is required for metastatic tumor dissemination. We show here in a model for TF-dependent experimental hematogenous metastasis, that TF supports metastasis by both proteolytic activity of the TF-VIIa complex and currently undefined functions of the cytoplasmic domain. We demonstrate that ligand binding of VIIa to TF is required for metastasis. Antimetastatic properties of covalently inactivated VIIa provide evidence that ligand binding is insufficient per se to support metastasis, emphasizing that proteolytic activity is necessary for the metastatic process. Ala or Asp mutations of cytoplasmic serine residues were introduced to preclude or mimic phosphorylation. In vivo analysis of these mutants suggests that local protease generation on the tumor cell surface does not serve simply to activate the cytoplasmic domain of TF by serine phosphorylation. Thus, extracellular functions of the catalytically active TF-VIIa complex cooperate with specific functions of the TF cytoplasmic domain to support the complex process of hematogenous tumor cell dissemination. (J. Clin. Invest. 1998. 101:1372-1378.) Key words: serine proteases • blood coagulation - signal transduction • site-directed mutagenesis
\end{abstract}

\section{Introduction}

The cellular activator of the coagulation pathway is the transmembrane protein tissue factor $(\mathrm{TF})^{1}$ that consists of a 219 amino acid extracellular domain, a 23-residue transmembrane domain, and a 21-residue intracellular domain. TF binds and allosterically activates factor VIIa (VIIa). The TF-VIIa com-

Address correspondence to Barbara M. Mueller, Ph.D., Department of Immunology, IMM-13, The Scripps Research Institute, $10550 \mathrm{~N}$. Torrey Pines Road, La Jolla, CA 92037. Phone: 619-784-8124; FAX: 619-784-2708; E-mail: bmueller@scripps.edu

Received for publication 16 June 1997 and accepted in revised form 15 January 1998.

1. Abbreviations used in this paper: $\mathrm{CHO}$, Chinese hamster ovary; SCID, severe combined immunodeficiency; TF, tissue factor; uPA, urokinase-type plasminogen activator; VIIa, factor VIIa; VIIai, inactivated VIIa.

J. Clin. Invest.

(C) The American Society for Clinical Investigation, Inc. 0021-9738/98/04/1372/07 \$2.00

Volume 101, Number 7, April 1998, 1372-1378

http://www.jci.org plex cleaves factor IX and X, leading to thrombin generation (1). The role of TF as a procoagulant activator is well understood in a variety of thromboembolic diseases, including gramnegative septicemia, acute coronary syndromes, and injuryinduced responses of the vessel wall $(2,3)$.

TF also plays important roles in embryonic vascular development and angiogenesis, but the requirement for its procoagulant function under these circumstances is currently not clear. The deletion of the TF gene in mice results in death of the embryo between embryonic days 8.5 and 10.5 . In one study, embryonic death has been attributed to the lack of TF-mediated hemostatic function, which results in bleeding and subsequent failure of the yolk sac vasculature (4). In another study, TF was suggested to be important for the development of the yolk sac vessel wall, as evidenced by a decreased number of pericytes at the time of vessel failure leading to the death of the embryo (5). This finding argues that TF may function predominantly to modify cellular function rather than mediating hemostasis. It is unclear whether TF activity in the embryonic vasculature involves presumed signaling functions of TF (6). Overexpression of TF in mouse fibrosarcoma cells results in the upregulation of the proangiogenic vascular endothelial growth factor and the downregulation of the antiangiogenic thrombospondin gene (7). In addition, these changes in gene expression result in better vascularized tumors in vivo, suggesting that TF functions in angiogenesis by activating intracellular signal transduction pathways, rather than by the extracellular triggering of the coagulation system.

It is also controversial whether the prometastatic functions of TF require the coagulation protease cascade. Many tumor cells express TF $(8,9)$, and several experimental systems support the idea that TF is important for the pathobiology and hematogenous metastasis of tumor cells (10). The consequence of factor Xa and thrombin generation by the TF-VIIa complex includes the formation of fibrin and signaling through cellular protease-activated receptors, both of which may influence the multistep process of metastasis (11-13). Consistent with an in vivo mechanism that requires proteolytic activity of the TFVIIa complex, function-blocking anti-TF antibodies (14), as well as specific inhibitors of coagulation proteases downstream of TF-VIIa such as factor Xa $(15,16)$ or thrombin $(15,17)$, block hematogenous metastasis of human or mouse melanoma cells. The procoagulant activity of the murine tumor cells used in these studies is likely TF (17).

However, prometastatic functions of TF have also been shown to depend on the short cytoplasmic domain (18), which does not influence cellular procoagulant functions of TF (19). In addition, mutation of residues Lys165 and Lys166, which severely impairs coagulant functions of TF, had no effect on TFdependent metastasis when tested by transfecting a melanoma cell line with low metastatic potential (18). Although controversial with a series of studies in various animal models demonstrating a requirement for protease generation in hematogenous metastasis, this study raises the possibility that TF may exhibit prometastatic functions independent of triggering the 
coagulation pathways, possibly involving signaling functions of TF.

Because of the broader implications for our understanding of TF functions in angiogenesis and embryonic vascular development, we considered it important to define in more detail the molecular pathways by which TF supports hematogenous metastasis. First, we addressed the question whether cell typespecific effects may account for the discrepant results in the literature. By studying the consequences of TF expression on the metastatic potential of Chinese hamster ovary $(\mathrm{CHO})$ cells in immune-deficient mice, we exclude cell type specificity as a reasonable explanation for the discrepancies. We further addressed the importance of ligand binding to TF for the metastatic process and demonstrate that binding of catalytically active VIIa is necessary for tumor cell metastasis. Thus, these data establish that the currently undefined functions of the TF cytoplasmic domain act in concert with rather than independent of the proteolytic function of TF.

\section{Methods}

Reagents. Recombinant human VIIa and Phe-Phe-Arg chloromethylketone inactivated VIIa (VIIai) were kindly provided by Dr. Mirella Ezban (Novo Nordisk A/S, Gentofte, Denmark). Mouse antihuman TF mAbs TF8-5G9 and TF9-10H10 have been described previously $(14,20)$. Fab fragments of these antibodies were prepared by papain digestion (20) followed by ion-exchange chromatography.

Mutagenesis and expression of TF. Site-directed mutagenesis of the TF coding region was performed as described (21). Mutations were confirmed by sequencing of CsCl-purified plasmid DNA, which was used subsequently for the transfection experiments. CHO cells (CHO-K1; American Type Culture Collection, Rockville, MD) were transfected using the calcium phosphate precipitation method. Stable cell lines were generated by cotransfecting a neomycin resistance gene (pMAMneo) with the TF-encoding plasmid followed by selection of clonal cell lines in G418 (GIBCO BRL, Gaithersburg, MD). Stable clones were tested for TF surface expression by staining with anti-TF mAbs using flow cytometry (21). TF expression was quantified by determining TF concentration in cell extracts by ELISA (22).

Functional characterization of TF mutants. Clotting activity was determined in a one-stage clotting assay as described (22). Briefly, cells were lysed in $15 \mathrm{mM}$ octyl- $\beta$-D-glucopyranoside, diluted 1:3 to reduce the detergent concentration, and clotting times were determined in a plasma clotting assay (equal volumes of lysate, plasma, and $20 \mathrm{mM} \mathrm{CaCl}_{2}$ ). Clotting times were converted to units based on a calibration curve using purified and phospholipid-reconstituted hu- man TF. For the experiments with human plasma, a pool of normal donor citrated plasma was used. Clotting times in murine plasma were determined using lyophilized citrated mouse plasma (Sigma Chemical Co., St. Louis, MO). Factor Xa generation by TF-VIIa was determined on monolayers of viable cells in a coupled amidolytic assay as described previously (21).

Experimental metastasis assay. Female C.B-17 severe combined immunodeficient (SCID) mice were purchased from Taconic Farms Inc. (Germantown, NY). Mice were housed under specific pathogenfree conditions and kept on $40 \mathrm{mg}$ trimethoprim and $200 \mathrm{mg}$ sulfamethoxazole per $300 \mathrm{ml}$ autoclaved drinking water. Cells were harvested from tissue culture and resuspended either in Dulbecco's PBS (1.5 $\mathrm{mM}$ monobasic potassium phosphate, $8 \mathrm{mM}$ dibasic potassium phosphate, $3 \mathrm{mM}$ potassium chloride, $137 \mathrm{mM}$ sodium chloride, $\mathrm{pH}$ 7.2) or, when indicated, in PBS containing antibodies or VIIai and incubated for $30 \mathrm{~min}$. Cells were subsequently injected in a $200-\mu \mathrm{l} \mathrm{vol-}$ ume into the lateral tail vein of 6-wk-old mice. Mice were killed $10 \mathrm{~d}$ later and examined for tumor growth. At this time, tumor foci were detected only in the lungs. Lungs were fixed in Bouin's solution, and tumor foci on the lung surface were counted under a low magnification microscope. When indicated, mice were injected intraperitoneally (i.p.) with VIIa or VIIai in $500 \mu \mathrm{l}$ PBS followed $1 \mathrm{~h}$ later by tail vein injection of cells.

To measure plasma concentrations of VIIa or VIIai after i.p. injection, blood was drawn retroorbitally in a heparinized capillary. The plasma was harvested by centrifugation, and VIIa concentration was determined from serial dilutions using an mAb-based ELISA specific for human VIIa (23). The various clonal lines were tested on at least two occasions, and a representative experiment is shown. For the cell lines $\mathrm{TF}_{\Delta \text { cyto }}, \mathrm{TF}_{\mathrm{A} 20 \mathrm{~A} 44 \mathrm{~A} 140 \mathrm{~A} 165 \mathrm{~A} 166}$, and $\mathrm{TF}_{\mathrm{A} 253 \mathrm{~A} 258}$, two independent clonal lines were analyzed. Only one clone with stable expression levels was available for wild-type $\mathrm{CHO} / \mathrm{TF}, \mathrm{TF}_{\mathrm{A} 165 \mathrm{~A} 166}$, $\mathrm{TF}_{\mathrm{A} 20 \mathrm{~A} 44 \mathrm{~A} 140}$, and $\mathrm{TF}_{\mathrm{D} 253 \mathrm{D} 258 \mathrm{D} 263}$.

\section{Results}

It has been useful to express cell surface molecules that are thought to play a role in tumor cell behavior in $\mathrm{CHO}$ cells to study their biological functions in vivo (24). To distinguish between the contribution of protease generation and signaling to the prometastatic role of TF, we stably transfected CHO-K1 cells with constructs that encode for wild-type human TF or one of the following mutants: (a) $\mathrm{TF}_{\mathrm{A} 165 \mathrm{~A} 166}$, an Ala replacement mutant of TF residues Lys165 and Lys166 with a selective loss of proteolytic function (22); (b) $\mathrm{TF}_{\mathrm{A} 20 \mathrm{~A} 44 \mathrm{~A} 140}$, an Ala replacement mutant of residues Lys20, Asp44, and Phe140 that has $>10,000$-fold reduced affinity for VIIa (25); (c)

Table I. Characterization of CHO Cells Expressing Mutant TF

\begin{tabular}{|c|c|c|c|c|}
\hline Mutation & Cell line & TF antigen & Mean fluorescence & Positive cells \\
\hline & & $n g / 10^{6}$ cells & $\%$ of $\mathrm{CHO} / \mathrm{TF}$ & $\%$ of total \\
\hline & CHO-K1 & Not detectable & 1 & $<1$ \\
\hline Wild-type & $\mathrm{CHO} / \mathrm{TF}$ & $65 \pm 17$ & 100 & $>99$ \\
\hline Lys165,Lys166 $\rightarrow$ Ala & $\mathrm{TF}_{\mathrm{A} 165 \mathrm{~A} 166}$ & $31 \pm 5$ & 85 & $>99$ \\
\hline Lys20,Asp44,Phe140 $\rightarrow$ Ala & $\mathrm{TF}_{\mathrm{A} 20 \mathrm{~A} 44 \mathrm{~A} 140}$ & $25 \pm 11$ & 36 & 88 \\
\hline Lys20,Asp44,Phe140,Lys165,Lys166 $\rightarrow$ Ala & $\mathrm{TF}_{\mathrm{A} 20 \mathrm{~A} 44 \mathrm{~A} 140 \mathrm{~A} 165 \mathrm{~A} 166}$ & $99 \pm 3$ & 158 & $>99$ \\
\hline Lys $244 \rightarrow$ stop & $\mathrm{TF}_{\Delta \text { cyto }}$ & $23 \pm 4$ & 48 & 94 \\
\hline Ser253,Ser258 $\rightarrow$ Ala & $\mathrm{TF}_{\mathrm{A} 253 \mathrm{~A} 258}$ & $28 \pm 8$ & 57 & 98 \\
\hline Ser253,Ser258,Ser263 $\rightarrow$ Asp & $\mathrm{TF}_{\mathrm{D} 253 \mathrm{D} 258 \mathrm{D} 263}$ & $76 \pm 11$ & 123 & $>99$ \\
\hline
\end{tabular}

TF antigen was determined in cell lysates by ELISA using two TF-specific mAbs. Flow cytometry was used to detect TF cell surface expression on intact cells after staining with anti-TF mAb and indirect detection with FITC-labeled anti-mouse antibody. 
$\mathrm{TF}_{\mathrm{A} 20 \mathrm{~A} 44 \mathrm{~A} 140 \mathrm{~A} 165 \mathrm{~A} 166}$, which combined the defects of the two previous mutants; or $(d) \mathrm{TF}_{\Delta \text { cyto }}$, a cytoplasmic domain deletion mutant, generated by conversion of the codon for Lys 244 to a termination codon. The cell line expressing wild-type TF $(\mathrm{CHO} / \mathrm{TF})$ was determined earlier to express $\sim 450,000 \mathrm{TF}$ molecules per cell (22). Stably transfected clonal $\mathrm{CHO}$ cell lines were established that expressed similar amounts of mutant TF, as measured by ELISA in cell lysates and by indirect immunofluorescence with TF-specific antibodies (Table I). The close correlation between total cellular TF content, as measured by ELISA, and cell surface expression, as measured by flow cytometry on nonpermeabilized cells, indicates that the introduced mutations, in particular the cytoplasmic domain deletion, did not significantly affect cell surface localization and intracellular trafficking of TF.

Function of the stable cell lines expressing mutant TF was determined in a one-stage clotting assay of detergent cell lysates using human or mouse plasma, and in a factor Xa generation assay on monolayers of intact cells. The cytoplasmic deletion mutant $\mathrm{TF}_{\Delta \text { cyto }}$ had proteolytic activity similar to the wild-type $\mathrm{CHO} / \mathrm{TF}$ line, emphasizing that this mutant is expressed on intact cell surfaces as a fully functional molecule (Table II). Proteolytic activities of mutants with reduced VIIa affinity, $\mathrm{TF}_{\mathrm{A} 20 \mathrm{~A} 44 \mathrm{~A} 140}$ and $\mathrm{TF}_{\mathrm{A} 20 \mathrm{~A} 44 \mathrm{~A} 140 \mathrm{~A} 165 \mathrm{~A} 166}$, were very low, whereas the mutant with reduced affinity for substrate, $\mathrm{TF}_{\mathrm{A} 165 \mathrm{~A} 166}$, retained $\sim 20 \%$ function compared with $\mathrm{CHO} / \mathrm{TF}$ (Table II). The procoagulant activities of cell lysates of these lines in mouse and human plasma showed good correlation with the proteolytic function on intact cells, with the exception of mutants in which Lys165 and Lys166 were replaced. Consistent with previous data $(18,22)$, the $\mathrm{TF}_{\mathrm{A} 165 \mathrm{~A} 166}$ mutant had $<1 \%$ coagulant function in human plasma. However, this mutant displayed 50-fold higher procoagulant activity in mouse plasma, retaining $\sim 17 \%$ of the wild-type $\mathrm{CHO} / \mathrm{TF}$ coagulant function, in agreement with the loss of function in the proteolytic assay. The low coagulant function in human plasma is likely a consequence of the importance of the mutated and adjacent residues in supporting VII to VIIa conversion, which is critical for TF clotting times in human plasma (26). The low clotting activity of $\mathrm{TF}_{\mathrm{A} 165 \mathrm{~A} 166}$ in human plasma has been taken as evidence that the downstream coagulation protease cascade is not triggered by this mutant (18). The significant residual proteolytic function and clotting activity in mouse plasma suggest that the $\mathrm{TF}_{\mathrm{A} 165 \mathrm{~A} 166}$ mutant has only limited value to assess

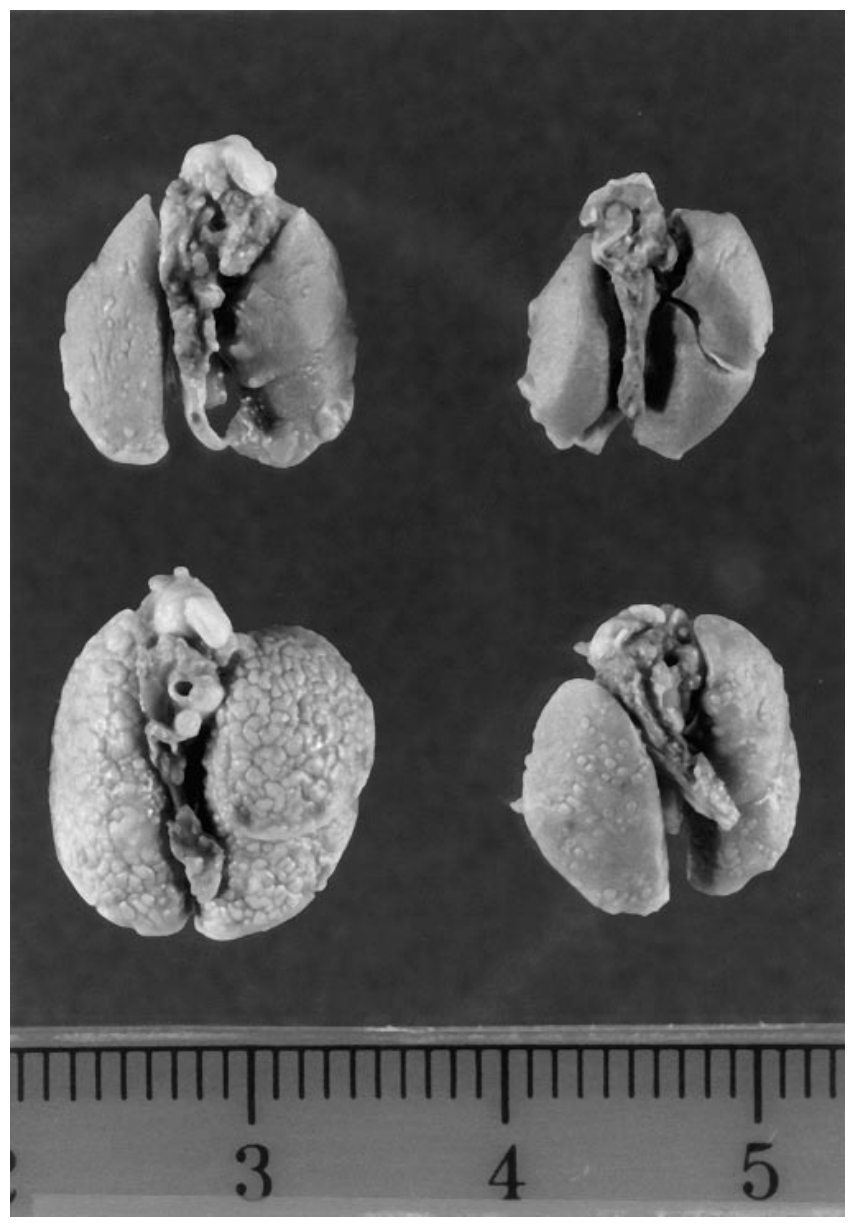

Figure 1. Experimental metastasis of $\mathrm{CHO}$ cells expressing TF. CHO-K1 cells (top) or $\mathrm{CHO} / \mathrm{TF}$ cells (bottom) at $10^{6}$ cells/animal (left) or $2.5 \times 10^{5}$ cells/animal (right) were injected into the lateral tail vein of 6-wk-old female SCID mice. Mice were killed $10 \mathrm{~d}$ later, and lungs were fixed in Bouin's solution.

the contributions of TF proteolytic activity to TF prometastatic functions in murine animal models.

$\mathrm{CHO}$ cells expressing full-length human TF were markedly more metastatic in immune-deficient SCID mice than parental CHO-K1 cells. For example, tail vein injection of $2.5 \times 10^{5}$

Table II. Functional Characterization of CHO Cells Expressing Mutant TF

\begin{tabular}{|c|c|c|c|c|}
\hline Mutation & Cell line & Xa generation & Clotting human plasma & Clotting mouse plasma \\
\hline & & $p M / \min$ & $m U / 10^{6}$ cells & $m U / 10^{6}$ cells \\
\hline & CHO-K1 & $2 \pm 1$ & $0.14 \pm 0.02$ & $17 \pm 1$ \\
\hline Wild-type & $\mathrm{CHO} / \mathrm{TF}$ & $784 \pm 448$ & $8438 \pm 1136$ & $10234 \pm 1867$ \\
\hline Lys165,Lys166 $\rightarrow$ Ala & $\mathrm{TF}_{\mathrm{A} 165 \mathrm{~A} 166}$ & $164 \pm 119$ & $31 \pm 3$ & $1770 \pm 246$ \\
\hline Lys20,Asp44,Phe140 $\rightarrow$ Ala & $\mathrm{TF}_{\mathrm{A} 20 \mathrm{~A} 44 \mathrm{~A} 140}$ & $38 \pm 35$ & $85 \pm 8$ & $51 \pm 7$ \\
\hline Lys20,Asp44,Phe140,Lys165,Lys166 $\rightarrow$ Ala & $\mathrm{TF}_{\mathrm{A} 20 \mathrm{~A} 44 \mathrm{~A} 140 \mathrm{~A} 165 \mathrm{~A} 166}$ & $30 \pm 29$ & $0.5 \pm 0.1$ & $15 \pm 2$ \\
\hline Lys244 $\rightarrow$ stop & $\mathrm{TF}_{\Delta \text { cyto }}$ & $615 \pm 332$ & $3427 \pm 238$ & $5725 \pm 521$ \\
\hline Ser253,Ser258 $\rightarrow$ Ala & $\mathrm{TF}_{\mathrm{A} 253 \mathrm{~A} 258}$ & $485 \pm 148$ & $4751 \pm 793$ & $6188 \pm 1343$ \\
\hline Ser253,Ser258,Ser263 $\rightarrow$ Asp & $\mathrm{TF}_{\mathrm{D} 253 \mathrm{D} 258 \mathrm{D} 263}$ & $722 \pm 115$ & $6895 \pm 1811$ & $8325 \pm 2247$ \\
\hline
\end{tabular}

Factor Xa generation was measured on monolayers of intact cells. Clotting activity of detergent lysates was determined in a one-stage clotting assay, and clotting times were converted into units of TF activity using a calibration curve of phospholipid-reconstituted recombinant TF. 
Table III. Experimental Metastasis of CHO Cells Expressing Wild-type or Mutant TF

\begin{tabular}{clll}
\hline \multicolumn{1}{c}{ Cell line } & \multicolumn{1}{c}{ Antibody } & \multicolumn{1}{c}{ Pulmonary foci } & \multicolumn{1}{c}{$P$} \\
\hline Experiment 1 & & & \\
$\mathrm{CHO} / \mathrm{TF}$ & None & $140,148,149,198,234,237$ & \\
$\mathrm{TF}_{\Delta \mathrm{cyto}}$ & None & $3,6,7,16,17,19$ & 0.0022 \\
$\mathrm{TF}_{\mathrm{A} 165 \mathrm{~A} 166}$ & None & $182,199,246,261,295,301$ & 0.041 \\
$\mathrm{CHO}$ 1 & None & $0,0,0,0,0,1$ & 0.0022 \\
Experiment 2 & & & \\
$\mathrm{CHO} / \mathrm{TF}$ & None & $109,142,174,194$ & \\
$\mathrm{CHO} / \mathrm{TF}$ & TF8-5G9 & $10,12,13,16$ & 0.0285 \\
$\mathrm{CHO} / \mathrm{TF}$ & TF9-10H10 & $137,180,181,186$ & $>0.5$ \\
& & & \\
\hline
\end{tabular}

$2.5 \times 10^{5}$ cells per mouse were injected i.v. into SCID mice. When indicated, cells were preincubated with $1 \mathrm{mg}$ antibody Fab fragment per $2.5 \times$ $10^{5}$ cells for 30 min before i.v. injection. $P$, Probability of no difference to control group in the Wilcoxon rank sum test.

$\mathrm{CHO} / \mathrm{TF}$ cells resulted in multiple distinct tumor foci on the lungs of SCID mice, whereas injection of the same number of parental CHO-K1 cells resulted in no visible foci (Fig. 1). The cytoplasmic deletion mutant, $\mathrm{TF}_{\Delta \mathrm{cyto}}$, was unable to generate enhanced lung metastasis (Table III) despite normal proteolytic and procoagulant activity. $\mathrm{TF}_{\mathrm{A} 165 \mathrm{~A} 166}$, which has somewhat reduced proteolytic and coagulant function but binds VIIa normally (22), did support metastasis (Table III). The metastatic behavior of $\mathrm{TF}_{\Delta \text { cyto }}$ and $\mathrm{TF}_{\mathrm{A} 165 \mathrm{~A} 166}$ was similar to what Bromberg et al. (18) described for mutant TF expressed in human melanoma cells, demonstrating that the requirement for the cytoplasmic domain of TF in metastasis is not cell type specific.

We have previously used specific mAbs against TF to demonstrate that a proteolytically active TF-VIIa complex is required for experimental metastasis of human melanoma cells (14). Antibody TF8-5G9 has potent anticoagulant activity by binding to the preformed TF-VIIa complex at an epitope that includes Lys165 and Lys166, thus competing for factor X access and activation (20). Antibody TF9-10H10 binds to a partially overlapping epitope on human TF, but does not inhibit binding of VIIa or the function of the TF-VIIa complex. To eliminate the possibility of $\mathrm{Fc}$-mediated destruction of antibody-coated cells, $\mathrm{CHO} / \mathrm{TF}$ cells were preincubated with $\mathrm{Fab}$ fragments of either TF8-5G9 or TF9-10H10 to study their effect on TF prometastatic function. The function-blocking antibody TF8-5G9 inhibited the number of pulmonary foci produced by TF-expressing $\mathrm{CHO}$ cells by $>90 \%$ (Table II). In contrast, the noninhibitory antibody TF9-10H10 had no effect on the metastasis of $\mathrm{CHO} / \mathrm{TF}$ cells. Thus, expressing $\mathrm{TF}$ in $\mathrm{CHO}$ cells results in enhanced experimental metastasis, and TF-dependent metastasis in this model has the same functional requirements as TF-dependent metastasis in other tumor models $(14,18)$.

VIIa binding to TF is essential for TF to function as a proteolytic cofactor. Therefore, we tested the metastatic behavior of TF mutants with $>10,000$-fold reduced VIIa binding capability. We found that TF mutants with decreased affinity for VIIa, $\mathrm{TF}_{\mathrm{A} 20 \mathrm{~A} 44 \mathrm{~A} 140}$ and $\mathrm{TF}_{\mathrm{A} 20 \mathrm{~A} 44 \mathrm{~A} 140 \mathrm{~A} 165 \mathrm{~A} 166}$, were unable to support metastasis (Table IV). Interestingly, $\mathrm{TF}_{\mathrm{A} 20 \mathrm{~A} 44 \mathrm{~A} 140 \mathrm{~A} 165 \mathrm{~A} 166}$, which combined the defect in VIIa binding with decreased
Table IV. Experimental Pulmonary Metastasis of CHO Cells Expressing Mutant TF

\begin{tabular}{llc}
\hline \multicolumn{1}{c}{ Cell line } & \multicolumn{1}{c}{ Pulmonary foci } & $P$ \\
\hline $\mathrm{CHO} / \mathrm{TF}$ & $78,93,107,123,149,194$ & \\
$\mathrm{TF}_{\mathrm{A} 20 \mathrm{~A} 44 \mathrm{~A} 140}$ & $3,3,7,9,10,18$ & 0.0022 \\
$\mathrm{TF}_{\text {A20A44A140A165A166 }}$ & $0,0,1,2,2,3$ & 0.0022 \\
\hline
\end{tabular}

$2.5 \times 10^{5}$ cells per mouse were injected i.v. into SCID mice. $P$, Probability of no difference to $\mathrm{CHO} / \mathrm{TF}$ in the Wilcoxon rank sum test.

proteolytic activity, also generated the smallest number of metastases. However, the requirement for VIIa binding may be due to signaling induced by ligand binding to TF. To test whether VIIa binding to TF is sufficient to support metastasis, we tested the effect of forming a complex of TF with covalently inactivated human recombinant VIIa (VIIai). Preincubating $\mathrm{CHO} / \mathrm{TF}$ cells with VIIai at concentrations between 10 and $0.01 \mu \mathrm{M}$ resulted in a dose-dependent inhibition of metastasis (Table V), excluding that ligand binding is sufficient to support metastasis. We also found no toxic effect of VIIai, since incubation of $\mathrm{CHO} / \mathrm{TF}$ cells with VIIai under tissue culture conditions for as long as $48 \mathrm{~h}$ did not affect cell viability or cell proliferation.

To exclude that the binding of VIIai before injection of the tumor cells induced a signal followed by a refractory state in which cells fail to metastasize, animals were also systemically anticoagulated with VIIai. Assembly and binding of inhibitor under these conditions follows the same kinetics as the natural ligand VIIa that circulates in the blood. Systemic administration of 500 or $50 \mu \mathrm{g}$ VIIai to mice before injecting $\mathrm{CHO} / \mathrm{TF}$ cells prevented pulmonary metastasis (Table $\mathrm{V}$ ), presumably by competing with endogenous mouse VIIa for binding to TF. Intravenous (i.v.) administration of VIIai before tumor cell injections was also effective (data not shown). However, VIIai may also compete with an unknown ligand of TF that is re-

Table V. Effect of VIIai on Experimental Metastasis of CHO/TF Cells

\begin{tabular}{lll}
\hline \multicolumn{1}{c}{ Treatment } & \multicolumn{1}{c}{ Pulmonary foci } & \multicolumn{1}{c}{$P$} \\
\hline Experiment 1 & & \\
PBS & $301,322,353,455,476$ & \\
$10 \mu$ M VIIai & $5,5,6,6,7$ & 0.0079 \\
$1 \mu$ M VIIai & $0,7,12,15,22$ & 0.0079 \\
$0.1 \mu$ M VIIai & $87,114,136,155,165$ & 0.0079 \\
$0.01 \mu$ M VIIai & $244,265,303,323,368$ & 0.22 \\
Experiment 2 & & \\
PBS & $176,304,317,337,355,365,407$ & \\
$500 \mu$ g VIIai & $0,0,1,2,4,5,24$ & 0.00058 \\
$50 \mu$ g VIIai & $1,2,4,5,10,13,63$ & 0.00058 \\
$500 \mu$ g VIIa & $128,141,226,237,311,325,340$ & 0.097 \\
& & \\
\hline
\end{tabular}

$\mathrm{CHO} / \mathrm{TF}$ cells $\left(2.5 \times 10^{5}\right.$ in $200 \mu \mathrm{l}$ PBS per mouse $)$ were either preincubated with VIIai for 30 min before i.v. injection (experiment 1) or injected into SCID mice that had received $1 \mathrm{~h}$ earlier an i.p. injection of VIIa or VIIai in $500 \mu$ l PBS (experiment 2). $P$, Probability of no difference to the untreated controls in the Wilcoxon rank sum test. 
Table VI. Plasma Levels of VIIai and VIIa after i.p. Injection

\begin{tabular}{lcc}
\hline Time after i.p. injection & VIIai concentration & VIIa concentration \\
\hline$h$ & $\mu g / m l$ & $\mu g / m l$ \\
1 & $32.9 \pm 11.5$ & $19.2 \pm 4.8$ \\
2 & $53.9 \pm 6.5$ & $45.8 \pm 22.9$ \\
6 & $29.5 \pm 11.8$ & $10.8 \pm 5.4$ \\
\hline
\end{tabular}

Each animal received a 250- $\mu$ g i.p. injection of recombinant human VIIai or VIIa at time 0. Heparinized blood was obtained from retroorbital blood drawing, and the plasma concentration of VIIai or VIIa was determined by an mAb sandwich ELISA specific for human VIIa. Mean \pm SD for three animals is given.

quired for metastasis. This competition should be mimicked by high concentrations of active VIIa. Systemic administration of $500 \mu \mathrm{g}$ human recombinant VIIa did not inhibit metastasis of $\mathrm{CHO} / \mathrm{TF}$ cells. Note in this regard that VIIai binds with an approximately fivefold higher affinity to TF than VIIa (27), and therefore, the 500- $\mu \mathrm{g}$ dose of VIIa should be compared to $50 \mu \mathrm{g}$ VIIai. At this concentration, VIIai was an effective inhibitor of tumor cell dissemination. Furthermore, VIIai and VIIa were both absorbed efficiently after i.p. injection and showed similar plasma levels during the injection phase of the tumor cells, which was $1 \mathrm{~h}$ after i.p. administration (Table VI). Earlier studies had shown that protease generation needs to be inhibited for $\sim 1 \mathrm{~h}$ during the injection phase of the tumor cells in order to prevent metastasis formation (17).

TF-dependent activation of coagulation proteases leads to the activation of signaling protease receptors, including the thrombin receptor (15). Signaling through protease-activated receptors may result in the phosphorylation of Ser residues of the TF cytoplasmic domain and thus support the prometastatic function of the cytoplasmic domain. To analyze the role of phosphorylation of the TF cytoplasmic domain in supporting TF prometastatic functions, we introduced Ala replacements for Ser253 and Ser258 which are phosphorylated in response to phorbol ester stimulation and which are conserved phosphorylation acceptor residues among species (28). The mutant was expressed at high levels and normal functional activities (Tables I and II). The $\mathrm{TF}_{\mathrm{A} 253 \mathrm{~A} 258}$ mutants consistently produced a lower number of metastases than the wild-type $\mathrm{CHO}$ / TF line (Table VII). However, the loss of function is much less severe than that observed for the cytoplasmic domain deletion

Table VII. Experimental Pulmonary Metastasis of CHO Cells Expressing Cytoplasmic Domain Ser $\rightarrow$ Ala Mutant of TF

\begin{tabular}{clc}
\hline Cell line & \multicolumn{1}{c}{ Pulmonary foci } & $P$ \\
\hline Experiment 1 & & \\
$\mathrm{CHO} / \mathrm{TF}$ & $109,142,174,194$ & \\
$\mathrm{TF}_{\mathrm{A} 253 \mathrm{~A} 258}$ & $58,74,75,79$ & 0.0022 \\
Experiment 2 & & \\
$\mathrm{CHO} / \mathrm{TF}$ & $370,383,387,484,485$ & \\
$\mathrm{TF}_{\mathrm{A} 253 \mathrm{~A} 258}$ & $155,162,278,308,377$ & 0.0158 \\
\hline
\end{tabular}

$2.5 \times 10^{5}$ cells per mouse were injected i.v. into SCID mice. $P$, Probability of no difference to $\mathrm{CHO} / \mathrm{TF}$ in the Wilcoxon rank sum test.
Table VIII. Experimental Metastasis of CHO Cells Expressing Mutant TF with a Pseudophosphorylated Cytoplasmic Domain

\begin{tabular}{lclc}
\hline \multicolumn{1}{c}{ Cell line } & Treatment & \multicolumn{1}{c}{ Pulmonary foci } & \multicolumn{1}{c}{$P$} \\
\hline CHO/TF & PBS & $212,254,274,310,322,350$ & $>0.5$ \\
$\mathrm{TF}_{\mathrm{D} 253 \mathrm{D} 258 \mathrm{D} 263}$ & PBS & $235,257,285,290,336,383$ & \\
$\mathrm{TF}_{\mathrm{D} 253 \mathrm{D} 258 \mathrm{D} 263}$ & VIIai & $0,4,5,14,15,18$ & 0.0022
\end{tabular}

$2.5 \times 10^{5}$ cells per mouse were preincubated either for 30 min with 10 $\mu \mathrm{M}$ VIIai or in PBS and were injected i.v. into SCID mice. $P$, Probability of no difference to $\mathrm{TF}_{\mathrm{D} 253 \mathrm{D} 258 \mathrm{D} 263}$ in the Wilcoxon rank sum test.

mutant, which essentially lost prometastatic functions. These data argue that phosphorylation of these Ser residues, although possibly supporting metastasis, is not absolutely required for TF prometastatic functions. We also generated a mutant TF in which the cytoplasmic Ser residues had been replaced with Asp to increase the negative charge at these positions, which may mimic phosphorylation while maintaining the side chain geometry. This mutant, $\mathrm{TF}_{\mathrm{D} 253 \mathrm{D} 258 \mathrm{D} 263}$, was expressed in $\mathrm{CHO}$ cells at similar levels and with similar proteolytic activity as wild-type TF (Tables I and II) and formed experimental pulmonary metastasis in SCID mice to the same extent as $\mathrm{CHO} / \mathrm{TF}$ cells (Table VIII). Metastasis of $\mathrm{TF}_{\mathrm{D} 253 \mathrm{D} 258 \mathrm{D} 263}$ was inhibited when cells were preincubated with VIIai (Table VIII), demonstrating that cells expressing this mutant still require the assembly of a proteolytically active TF-VIIa complex for efficient metastasis. These data suggest that proteolytic function is probably not solely required for phosphorylation of the TF cytoplasmic domain. Rather, it appears that prometastatic functions of TF depend on the catalytically active TF-VIIa complex acting in concert with undefined functions of the cytoplasmic domain of TF.

\section{Discussion}

We demonstrate here that transfection of $\mathrm{CHO}$ cells with $\mathrm{TF}$ enhances experimental tumor cell metastasis, as shown previously for human melanoma. TF-dependent metastasis of $\mathrm{CHO}$ cells required the TF cytoplasmic domain but was also blocked selectively by inhibitory antibodies to TF. Thus, this model recapitulates all previous data, emphasizing that TF prometastatic functions are dependent on both extracellular proteolytic activity and currently undefined functions of the cytoplasmic domain of TF. We confirm here that expression of a $\mathrm{TF}$ mutant, $\mathrm{TF}_{\mathrm{A} 165 \mathrm{~A} 166}$, which is essentially devoid of procoagulant function in human plasma, fully supports TF-dependent metastasis (18). We demonstrate that this mutant retains coagulant activity in mouse plasma to a degree consistent with its only fivefold reduced proteolytic function, as measured with purified proteins on intact cells. We conclude that this residual function is sufficient to support the metastatic process.

Mutation of three of the key contact residues in TF for its ligand VIIa essentially abolished TF-dependent metastasis, demonstrating the essential role of ligand binding in the metastatic process. These data may indicate that VIIa binding cooperates with functions of the cytoplasmic domain, which is equally essential for metastasis. We exclude that ligand VIIa binding is sufficient per se to support TF-dependent metasta- 
sis, by demonstrating antimetastatic properties of covalently inactivated VIIai, which binds tightly to TF. Furthermore, high concentrations of active VIIa administered to the mice did not block metastasis, excluding that the inhibitory action of VIIai is through competition with an unknown ligand for TF. Thus, formation of a catalytically active TF-VIIa complex is required for metastasis. The severe loss of coagulant function after disruption of VIIa binding, together with earlier studies (14-17), thus strongly supports the concept that the prometastatic functions of TF involve the generation of downstream proteolytic activity.

Tumor cell metastasis is viewed as a multistep process that involves intravasation of tumor cells from the primary tumor, survival in the circulation, arrest in the microcirculation, extravasation, and tumor growth in the secondary site $(11,12)$. From clinical observations and experimental studies, it appears that metastasis is inherently an inefficient process (29), but it is controversial what steps in the metastatic process are rate-limiting (30). TF expression contributes to the likelihood that a cell overcomes one or more rate-limiting steps in metastasis. There are several potential targets for proteases, most notably thrombin, that are generated by the TF-VIIa complex on the tumor cell surface. Thrombin may enhance tumor cell interactions with the vessel wall by upregulating cell-cell adhesion molecules, such as P-selectin and intercellular adhesion molecule 1, on endothelial cells (31) and by enhancing tumor cell adhesion to endothelial cells and the subendothelial matrix (32). If tumor cell extravasation is rate-limiting in metastasis, thrombin generation may facilitate this process by altering endothelial permeability $(33,34)$ or by upregulating matrix degradation (35).

Postextravasation migration to preferred sites in the parenchyma of the secondary organ may regulate the efficiency of tumor cell metastasis (36). Migration may be influenced by thrombin receptor activation, which alters the cytoskeleton organization by uncapping actin filament barbed ends (37), and enhances cell motility indirectly by inducing the production of chemotactic factors in vascular pericytes (38). The fate of a metastasizing cell may be determined by its ability to proliferate and grow a secondary tumor. Thrombin receptor signaling has been shown to induce proliferation of smooth muscle cells as well as metastatic tumor cells $(15,39,40)$. Finally, several of these pathways may also support angiogenic neovascularization of tumor metastases, a biological process regulated by TF expression on tumor cells (7).

Our data suggest that proteolytic function of the TF-VIIa complex does not serve simply to modulate the phosphorylation state of the TF cytoplasmic domain, but rather that TF has a dual function in metastasis, namely the assembly of a proteolytic complex and intracellular functions possibly related to signaling. Thus, TF serves as an example for the role of cell surface molecules in the regulation of the interactions between tumor cells and their extracellular environment. Another protease receptor with dual function in tumor cell biology is the receptor for the urokinase-type plasminogen activator (uPA). The uPA receptor enables invading cells to degrade the extracellular matrix by directing the proteolytic activity of uPA, enhancing its catalytic activity and protecting it from inactivation by protease inhibitors (41). However, uPA binding to the uPA receptor, independent of its catalytic activity, also initiates signal transduction events that lead to tumor cell activation and migration $(42,43)$. Another example of a cell surface molecule with more than one function in tumor biology is the integrin $\alpha v \beta 3$, which is a cellular adhesion receptor for matrix proteins containing an Arg-Gly-Asp motif. $\alpha \mathrm{v} \beta 3$ mediates cell adhesion and migration on extracellular matrices and thereby modulates the behavior of metastatic tumor cells as well as endothelial cells in angiogenic vessels (44). Recently, $\alpha v \beta 3$ was discovered also to function as a receptor for the matrix metalloproteinase MMP-2 (45), and therefore contributes to the proteolytic remodeling of extracellular matrices. Thus, the uPA receptor, the integrin $\alpha \mathrm{v} \beta 3$, and TF may be examples for an emerging paradigm, specifically that multiple and overlapping functions rather than a single distinct function of cell surface receptors coordinate the behavior of invasive cells in their extracellular environment.

\section{Acknowledgments}

We thank Cindi Biazak and Dorothy Markowitz for excellent technical assistance. We would like to express our sincere thanks to Dr. Mirella Ezban for generously providing recombinant VIIa and VIIai, and to the members of the Vessel Wall Biology Group at Novo Nordisk $\mathrm{A} / \mathrm{S}$ for assuring the quality of these important reagents.

This study was supported by National Institutes of Health grants CA-59692 (to B.M. Mueller) and HL-16411 (to W. Ruf). B.M. Mueller is the recipient of a Junior Faculty Research Award from the American Cancer Society, and W. Ruf is an Established Investigator of the American Heart Association. This is The Scripps Research Institute's manuscript 10913-IMM.

\section{References}

1. Ruf, W., and T.S. Edgington. 1994. Structural biology of tissue factor, the initiator of thrombogenesis in vivo. FASEB (Fed. Am. Soc. Exp. Biol.) J. 8:385-390.

2. Mackman, N. 1995. Regulation of the tissue factor gene. FASEB (Fed. Am. Soc. Exp. Biol.) J. 9:883-889.

3. Fuster, V., J. Badimon, J.H. Chesebro, and J.T. Fallon. 1996. Plaque rupture, thrombosis, and therapeutic implications. Haemostasis. 26:269-284.

4. Bugge, T.H., Q. Xiao, K.W. Kombrinck, M.J. Flick, K. Holmback, M.J. Danton, M.C. Colbert, D.P. Witte, K. Fujikawa, E.W. Davie, and J.L. Degen. 1996. Fatal embryonic bleeding events in mice lacking tissue factor, the cellassociated initiator of blood coagulation. Proc. Natl. Acad. Sci. USA. 93:62586262.

5. Carmeliet, P., N. Mackman, L. Moons, T. Luther, P. Gressens, I. van Vlaenderen, H. Demunck, M. Kasper, G. Breier, P. Evrard, et al. 1996. Role of tissue factor in embryonic blood vessel development. Nature. 383:73-75.

6. Masuda, M., S. Nakamura, T. Murakami, Y. Komiyama, and H. Takahashi. 1996. Association of tissue factor with a gamma chain homodimer of the IgE receptor type I in cultured human monocytes. Eur. J. Immunol. 26:25292532 .

7. Zhang, Y., Y. Deng, T. Luther, M. Muller, R. Ziegler, R. Waldherr, and P.P. Nawroth. 1994. Tissue factor controls the balance of angiogenic and antiangiogenic properties of tumor cells in mice. J. Clin. Invest. 94:1320-1327.

8. Rao, L.V.M. 1992. Tissue factor as a tumor procoagulant. Cancer Metastasis Rev. 11:249-266.

9. Rickles, F.R., G.A. Hair, R.A. Zeff, E. Lee, and R.D. Bona. 1995. Tissue factor expression in human leukocytes and tumor cells. Thromb. Haemost. 74: 391-395.

10. Ruf, W., and B.M. Mueller. 1996. Tissue factor in cancer angiogenesis and metastasis. Curr. Opin. Hematol. 3:379-384.

11. Fidler, I.J. 1990. Critical factors in the biology of human cancer metastasis: twenty-eighth G.H.A. Clowes memorial award lecture. Cancer Res. 50: 6130-6138.

12. Liotta, L.A., and W.G. Stetler-Stevenson. 1993. Principles of molecular cell biology of cancer: cancer metastasis. In Cancer: Principles and Practice of Oncology. V.T. DeVita, S. Hellman, and S.A. Rosenberg, editors. J.B. Lippincott Co., Philadelphia. 134-149.

13. Hakomori, S. 1996. Tumor malignancy defined by aberrant glycosylation and sphingo(glyco)lipid metabolism. Cancer Res. 56:5309-5318.

14. Mueller, B.M., R.A. Reisfeld, T.S. Edgington, and W. Ruf. 1992. Expression of tissue factor by melanoma cells promotes efficient hematogenous metastasis. Proc. Natl. Acad. Sci. USA. 89:11832-11836.

15. Fischer, E.G., W. Ruf, and B.M. Mueller. 1995. Tissue factor-initiated thrombin generation activates the signaling thrombin receptor on malignant 
melanoma cells. Cancer Res. 55:1629-1632.

16. Gasic, G.J., A. Iwakawa, T.B. Gasic, E.D. Viner, and L. Milas. 1984. Leech salivary gland extract from Haementeria officinalis, a potent inhibitor of cyclophosphamide- and radiation-induced artificial metastasis enhancement. Cancer Res. 44:5670-5676.

17. Esumi, N., D. Fan, and I.J. Fidler. 1991. Inhibition of murine melanoma experimental metastasis by recombinant desulfatohirudin, a highly specific thrombin inhibitor. Cancer Res. 51:4549-4556.

18. Bromberg, M.E., W.H. Konigsberg, J.F. Madison, A. Pawashe, and A. Garen. 1995. Tissue factor promotes melanoma metastasis by a pathway independent of blood coagulation. Proc. Natl. Acad. Sci. USA. 92:8205-8209.

19. Paborsky, L.R., I.W. Caras, K.L. Fisher, and C.M. Gorman. 1991. Lipid association, but not the transmembrane domain, is required for tissue factor activity. J. Biol. Chem. 266:21911-21916.

20. Ruf, W., and T.S. Edgington. 1991. An anti-tissue factor monoclonal antibody which inhibits TF.VIIa complex is a potent anticoagulant in plasma. Thromb. Haemost. 66:529-533.

21. Rehemtulla, A., W. Ruf, and T.S. Edgington. 1991. The integrity of the cysteine 186-cysteine 209 bond of the second disulfide loop of tissue factor is required for binding of factor VII. J. Biol. Chem. 266:10294-10299.

22. Ruf, W., D.J. Miles, A. Rehemtulla, and T.S. Edgington. 1992. Cofactor residues 165 and 166 are critical for protein substrate recognition by the tissue factor-factor VIIa protease complex. J. Biol. Chem. 267:6375-6381.

23. Ruf, W. 1994. Factor VIIa residue $\mathrm{Arg}^{290}$ is required for efficient activation of the macromolecular substrate factor X. Biochemistry. 33:11631-11636.

24. Matsuura, N., W. Puzon-McLaughlin, A. Irie, Y. Morikawa, K. Kakudo, and Y. Takada. 1996. Induction of experimental bone metastasis in mice by transfection of integrin $\alpha 4 \beta 1$ into tumor cells. Am. J. Pathol. 148:55-66.

25. Ruf, W., C.R. Kelly, J.R. Schullek, D.M.A. Martin, I. Polikarpov, C.W.G. Boys, E.G.D. Tuddenham, and T.S. Edgington. 1995. Energetic contributions and topographical organization of ligand binding residues of tissue factor. Biochemistry. 34:6310-6315.

26. Dittmar, S., W. Ruf, and T.S. Edgington. 1997. Influence of mutations in tissue factor on the fine specificity of macromolecular substrate activation. Biochem. J. 321:787-793.

27. Sorensen, B.B., E. Persson, P.O. Freskgard, M. Kjalke, M. Ezban, T. Williams, and L.V.M. Rao. 1997. Incorporation of an active site inhibitor in factor VIIa alters the affinity for tissue factor. J. Biol. Chem. 272:11863-11868.

28. Zioncheck, T.F., S. Roy, and G.A. Vehar. 1992. The cytoplasmic domain of tissue factor is phosphorylated by a protein kinase C-dependent mechanism. J. Biol. Chem. 267:3561-3564.

29. Weiss, L. 1990. Metastatic inefficiency. Adv. Cancer Res. 54:159-211.

30. Chambers, A.F., I.C. MacDonald, E.E. Schmidt, S. Koop, V.L. Morris, R. Khoka, and A.C. Groom. 1995. Steps in tumor metastasis: new concepts from intravital videomicroscopy. Cancer Metastasis Rev. 14:279-301.

31. Sugama, Y., C. Tiruppathi, K. Janakidevi, T.T. Andersen, J.W. Fenton II, and A.B. Malik. 1992. Thrombin-induced expression of endothelial P-selectin and intercellular adhesion molecule-1: mechanism for stabilizing neutrophil adhesion. J. Cell Biol. 119:935-944.

32. Klepfish, A., M.A. Greco, and S. Karpatkin. 1993. Thrombin stimulates melanoma tumor cell binding to endothelial cells and subendothelial matrix. Int. J. Cancer. 53:978-982.

33. Lum, H., T.T. Andersen, A. Silfinger-Birnboim, C. Tiruppathi, M.S Goligorsky, J.W. Fenton II, and A.B. Malik. 1993. Thrombin receptor peptide inhibits thrombin-induced increase in endothelial permeability by receptor desensitization. J. Cell Biol. 120:1491-1499.

34. Rabiet, M.J., J.L. Planties, Y. Rival, Y. Genoux, M.G. Lampugnani, and E. Dejana. 1996. Thrombin-induced increase in endothelial permeability is associated with changes in cell-to-cell junction organization. Arterioscler. Thromb. Vasc. Biol. 16:488-496.

35. Zucker, S., C. Conner, B.I. DiMassmo, H. Ende, M. Drews, M. Seiki, and W.F. Bahou. 1995. Thrombin induces the activation of progelatinase A in vascular endothelial cells. Physiologic regulation of angiogenesis. J. Biol. Chem. 270:23730-23738.

36. Morris, V.L., S. Loop, I.C. MacDonald, E.E. Schmidt, M. Grattan, D. Percy, A.F. Chambers, and A.C. Groom. 1994. Mammary carcinoma cell lines of high and low metastatic potential differ not in extravasation but in subsequent migration and growth. Clin. Exp. Metastasis. 12:357-367.

37. Hartwig, J.H., G.M. Bokoch, C.L. Carpenter, P.A. Janmey, L.A. Taylor, A. Toker, and T.P. Stossel. 1995. Thrombin receptor ligation and activated rac uncap actin filament barbed ends through phosphoinositide synthesis in permeabilized human platelets. Cell. 82:643-653.

38. Grandaliano, G., A.J. Valente, and H.E. Abboud. 1994. A novel biologic activity of thrombin: stimulation of monocyte chemotactic protein production. J. Exp. Med. 179:1737-1741.

39. McNamara, C.A., I.J. Sarembock, L.W. Gimple, J.W. Fenton II, S.R. Coughlin, and G.K. Owens. 1993. Thrombin stimulates proliferation of cultured aortic smooth muscle cells by a proteolytically activated receptor. J. Clin. Invest. 91:94-98.

40. Molloy, C.J., J.E. Pawlowski, D.S. Taylor, C.E. Turner, H. Weber, M. Peluso, and S.M. Seiler. 1996. Thrombin receptor activation elicits rapid protein tyrosine phosphorylation and stimulation of the raf-1/MAP kinase pathway preceding delayed mitogenesis in cultured rat aortic smooth muscle cells. $J$. Clin. Invest. 97:1173-1183.

41. Ellis, V., C. Pyke, J. Eriksen, H. Solberg, and K. Dano. 1992. The urokinase receptor: involvement in cell surface proteolysis and cancer invasion. Ann. NY Acad. Sci. 667:13-31.

42. Stahl, A., and B.M. Mueller. 1994. Binding of urokinase to its receptor promotes migration and invasion of human melanoma cells in vitro. Cancer Res. 54:3066-3071.

43. Resnati, M., M. Guttinger, S. Valcamonica, N. Sidenius, F. Blasi, and F. Fazioli. 1996. Proteolytic cleavage of the urokinase receptor substitutes for the agonist-induced chemotactic effect. EMBO (Eur. Mol. Biol. Organ.) J. 15:15721582.

44. Varner, J.A., and D.A. Cheresh. 1996. Integrins and cancer. Curr. Opin. Cell Biol. 8:724-730.

45. Brooks, P.C., S. Stromblad, L.C. Sanders, T.L. von Schalscha, R.T. Aimes, W.G. Stetler-Stevenson, J.P. Quigley, and D.A. Cheresh. 1996. Localization of matrix metalloproteinase MMP-2 to the surface of invasive cells by interaction with integrin $\alpha v \beta 3$. Cell. 85:683-693. 